\title{
CONSTRUCTIVISMO EN LAS TEORÍAS ACTUALES SOBRE LA JUSTICIA
}

\author{
Francisco CARPINTERo BenÍTEZ \\ Catedrático Emérito \\ Área de Filosofía del Derecho. \\ Departamento de Derecho Público \\ Facultad de Derecho. \\ Universidad de Cádiz \\ francisco.carpintero@uca.es
}

\section{INTRODUCCIÓN}

El fundamento sistemático de la filosofía del Derecho de la Edad Moderna - ya nos refiramos al contractualismo iluminista, ya al positivismo que estalló en el siglo XIX- no está en su punto de partida, sino en su punto de llegada. Estamos ante una circularidad en la que los elementos aparentemente finales adelantaban intrametódicamente lo que podía ser dicho en la reflexión sobre el Derecho, pues se trataba de crear un poder que, por el hecho de decidir según unas condiciones determinadas, volviera justo lo decidido. Este poder, así entendido, era el andamiaje que la conciencia misma aportaba para apuntalar el carácter sintético de sus construcciones en tanto que presentes ante ella misma. Era la representación moderna de la conciencia, que se presentaba como una conciencia de sí que se concibe absolutamente, de forma que el pensamiento puro aparece como algo que es frente a la conciencia misma, sin que permita alguna representación que se entienda que proviene más allá de ella.

Aunque aquellos autores pretendieron describirla, es preciso referirse a la naturaleza sintética de estas teorías porque los moderni propusieron definiciones genéticas o síntesis a priori. Estas síntesis consistían en presentar como dato primero un estado de cosas — normalmente los individuos aislados y carentes en el status naturae - que ya portaban en sí, insilogizados, los elementos que harían avanzar el desarrollo teoremático hasta alcanzar la meta aparentemente final. Esta capacidad para ir desde el comienzo hasta el final y desde el final hasta los inicios —una de las pri- 
meras exigencias metódicas que estableció Hobbes $-{ }^{1}$ era posible porque no había realmente una distinción entre los axiomas primeros, los elementos functores o los algoritmos intermedios y las conclusiones finales: la intención presente en todo momento, el prosilogismo, dirigía todos los pasos de la axiomatización. En otras palabras, propusieron constructos puramente intelectuales que fueron presentados como las leyes necesarias del psiquismo humano cuando conoce y elabora sus objetos en ese «espacio» tan peculiar que es el Derecho. Aunque, hablando con más precisión, no parece procedente hablar de objetos, en plural, sino sólo de alcanzar una meta única, pues estos pequeños talleres que son las definiciones genéticas únicamente pueden producir (reproducir o desarrollar) el dato inicial desde el que parten.

El lector no debe esperar ahora el desarrollo más o menos detenido de alguna faceta de estos constructos. Ya acometí este trabajo, quizá con demasiadas pretensiones ${ }^{2}$, y estas páginas no reclaman para sí más honor que el hacer una presentación miscelánea de problemas que emergen desde esta racionalidad que gira reiterativamente sobre sí misma y que, por decirlo así, se construye ella a sí misma sin aportar nada que no haya sido puesto autoritariamente en virtud del método y de los axiomas situados antes de iniciar el despliegue de lo aparentemente estudiado.

\section{LAS PERSONAS}

Un constructo es una propuesta doctrinal que normalmente toma como punto de partida un dato de lo que estudia y que desarrolla, a partir de este principium unicum, un cuerpo lógico que se basta a sí mismo. El mos geometricus seu arithmeticus decía partir desde un solo dato, y de ahí las teorías sobre el principio único y las controversias que levantaron en la Edad Moderna $^{3}$. Desde luego, si estudiamos aquellas obras nadie puede mante-

${ }^{1}$ Es coherente cuando afirma que la ciencia se limita a las apariencias de la naturaleza. Vid. T. Hobbes, Elements of Philosophy, London, Scientia, 1839, p. 388. Esto hace posible que la explicación de la ciencia vaya desde las causas a los efectos y desde los efectos a las causas: un proceso reversible. Vid. ibid., pp. 387-388.

2 Vid. F. Carpintero Benítez, La crisis del Estado en la edad posmoderna, Cizur Menor, Thomson Reuters-Aranzadi, 2012. Más recientemente íD., Dogmas y escepticismo. Presupuestos de filosofía del Derecho, México, Escuela Libre de Derecho-Porrúa, 2013.

3 Vid. Jacobus Fredericus LudovicI, Dubia circa hipothesis de principium iuris naturae eiusdemque vindicias, Leipzig, Vorbericht, 1709, $₫ 1$. Johann Fredericus Homberg, en una obra francamente crítica contra esta corriente del Derecho natural (la publicó anónima), 
ner que estuvo eficazmente operativo tal dato solitario, porque el Derecho parte desde datos diversos. Pero es fácil argumentar así si con ello un autor logra insertarse en la línea innovadora predominante y, de la mano de esta inserción, más política que científica, conseguir éxito académico.

Se dice usualmente que el Renacimiento de los siglos XV y XVI llevó hacia una mayor revalorización de los datos concretos y, en el mundo humano, a una revalorización de los individuos. Esto, expresado así, es tan cierto como falso. Al tratar de las personas, el mos geometricus sólo conocía puntos en el espacio uniforme, todos iguales. Exponían individuos, no personas, aunque establecieran que esos individuos estaban dotados de voluntad. Esta igualdad (aritmética o geométrica) fue el primer elemento que la conciencia moderna aportó para reclamar la igualdad de todos los seres humanos ante las leyes. No conocieron personas concretas que están solteras o casadas, que tienen hijos, que son propietarias, que ejercen una profesión, que compran o que venden. El Derecho romano adaptado a las circunstancias de aquel momento histórico - el Jus Commune - sí tenía en cuenta estas determinaciones (término casi hegeliano) de las personas, pero los innovadores rechazaron precisamente este partir desde las concreciones; en su lugar propusieron hacer andar a los argumentos de la mano de unos átomos de voluntad que viven en un tan abstracto como sin relieves status naturae.

Esta nueva noción de los seres humanos, ¿llevó hacia una reivindicación real de las individualidades, o más bien ocultó a las personas siempre concretas en unos conceptos de alcance, de hecho, universal? No es el momento de tratar de responder en su profundidad a un interrogante tan ambicioso. Notemos únicamente que los hombres quedamos diluidos en un noúmeno que afirmaba abstractamente la igualdad al mismo tiempo que desconocía las realidades tan plurales como concretas: afirmaba conceptos y desconocía a las personas en sus determinaciones reales. Tuvo razón Hegel cuando dedicó la primera parte de su Filosofía del Derecho a lo que él llamo derecho abstracto, que venía a ser, cabalmente, esta concepción de los individuos ${ }^{4}$ propia de la escuela del Derecho natural moderno. Las perso-

destacó que estos juegos del principio único «Nibil sunt nisi nugae, contradictiones, et marca semper mendacia» (J. F. HomBERG, Dubia iuris naturae, Hallae, 1719, \$15). L. MALQuYTIUS expuso sus críticas en Vera non simulata philosophia jurisconsultorum, Hallae, Magdeburgicae, 1729. Cuando los católicos reaccionaron contra el nervio secularizador de la Juris Naturalis Disciplina, aportaron críticas nuevas y más contundentes. Éste fue el caso, entre otros, de Ignatius Schwarz y Anselm Desing. Para estos últimos autores vid. L. CABrera, Modernidad y neoescolástica: Anselm Desing, Cádiz, Universidad de Cádiz, 2002.

${ }^{4}$ Hegel llamó Derecho abstracto a la representación de los individuos que había sido 
nas fueron sustituidas por teorías, y un ser humano sólo podía aspirar a ser un punto terminal o de atribución de las exigencias contenidas en cada una de esas teorías. Con razón, los discípulos de Kant —siguiendo el racionalismo wolffiano- nos llamaron a los hombres «esencias racionales» (vernünftige Wesen $)^{5}$, y con razón desde este presupuesto, Kelsen explicó que una persona es un concepto simplemente auxiliar (Hilfsbegriff) de la teoría del Derecho, ya que un ser humano es solamente un punto ideal de atribución (Zuscbreibung) de un sector de las normas del orden jurídico ${ }^{6}$.

Estamos en manos de teorías sobre la justicia, es decir, de noúmenos de hecho, y sólo se nos reconoce el derecho a que se nos apliquen las exigencias de estos constructos, que han tenido una historia paradójica: durante el siglo XIX y buena parte del Xx, la mayor parte de los que reflexionaron sobre el Derecho negaron la posibilidad de establecer criterios evaluadores de la justicia, fuera bajo la forma de una Rechtsphilosophie o de una Gesetzgebungswissenschaft ${ }^{\top}$ (pensemos en personas tan distintas como Knapp, Bergbohm o Kelsen), pero ante los abusos cometidos históricamente nos hemos separado de este estilo y nos hemos cargado de libros con exposiciones de derechos humanos y de teorías sobre la racionalidad práctica, de modo que, finalmente, los estudios sobre la razón práctica han llegado a ser una cosa muy poco práctica. Es un tópico admitido hoy que los estudios sobre los derechos y estas teorías sobre la justicia han clausurado el discurso político,

propia del Derecho natural moderno, es decir, a la idea de unos seres que pactaban libremente al margen de los datos de la realidad concreta, de forma que la categoría jurídica más decisiva era ante todo el contrato. Desde este punto de vista que desconoce las concreciones sólo tenemos a unos individuos que contratan poniendo su voluntad abstracta y quedando el contenido del contrato en manos de la simple contingencia, de forma que tanto se puede querer una cosa como su contraria.

5 Theodor Schmalz, entre otros discípulos de Kant, escribía: «Praktisch im engern Sinne heisst das, was sich auf die Zwecke eines vernünftigen Wesen bezieht, wieferne sie durch Freyheit oder nach Freyheitsgesetzen realisirt werde. Alles aber, was sich auf die Freyheit bezieht heisst moralisch---z.B. praktische Philosophie = Moralphilosophie». Cfr. Aphorismen zur Philosophie des Rechts, Jena, 1800, $\$ 13$.

${ }^{6}$ Alejandro Llano destacó la disolución de la persona en el pensamiento kantiano. Vid. A. Llano, La nueva sensibilidad, Madrid, Espasa-Calpe, 1988, p. 98. Fue lógico que Kelsen, imbuido en el mundo cuasinouménico que es propio de las normas consideradas cognitivamente, explicara que la persona jurídica es sólo el punto de «atribución» (Zuschreibung) de un sector de las normas del ordenamiento jurídico. Vid. H. KELSEN, Reine Rechtslebre, Wien, Frank Deuticke, 1960, $\$ 37$, p. 192. Este proceso ha continuado en nuestra generación posmoderna. Vid. B. Montanari, Itinerari di filosofia del diritto, Padova, Cedam, 1999, pp. 87 y ss. Esta referencia a Montanari la he tomado de la obra de Barbara TronCARelli, Complexità e diritto. Oltre la ragione sistemica, Milano, Giuffrè, 2002, p. 8. 1993.

7 Vid. mi estudio Los inicios del positivismo jurídico en Centroeuropa, Madrid, Actas, 
y esta insuficiencia daña seriamente al hombre de hoy. Si una persona es un ser que irrumpe en la vida con su propia oferta, y esta capacidad para innovar es un rasgo constitutivo de la personalidad, ¿dónde queda la cualidad personal de cada hombre? Ante un Estado con una Administración fuerte, un ciudadano puede alegar derechos concretos y ya previstos por el poder (un tanto al modo de los privilegios medievales), pero él, como ser autónomo, sólo es tenido en cuenta escasamente. Hasta cierto punto es lógico que sea así porque ese estado de homeóstasis o de falso equilibrio que desea cualquier político para actuar según su criterio quedaría roto por el reconocimiento de las competencias de otras capacidades creadoras ${ }^{8}$.

La tendencia a introducir teorías o noúmenos tiene alcances teóricos más amplios. Aludamos a lo más elemental: si en la filosofía práctica una teoría de éstas es un cuerpo doctrinal que se basta a sí mismo, sin estudiar todo aquello que le está vedado en virtud del método elegido tenemos derecho a preguntar: ¿dónde está ese punto en el que el sujeto se capta él a sí mismo siendo simultáneamente pensamiento objetivo y autonomía individual? Pues la posición de esa intuición determinará decisivamente los modos en los que la persona se considere a sí misma.

Ha sucedido históricamente que Descartes adoptó una actitud incoherente, pues tenía que haber optado entre el ego cogito o los cogitata impersonales; desde el «yo pienso» no se deduce ningún mundo lógico objetivo" y desde el mundo lógico universal y por ello impersonal no se llega al yo,

${ }^{8}$ Bertalanffy explica que el problema de los sistemas es esencialmente el problema de las limitaciones de los procedimientos analíticos en la ciencia. Vid. L. vON BERTALANFFy, Teoría general de los sistemas. Fundamentos, desarrollo, aplicaciones, trad. de J. Almela, México, FCE, 1989, p. 17. Efectivamente, las relaciones entre las partes de un grupo existen, y estas relaciones no son unidireccionales ni lineales. Bertalanffy denuncia a la física clásica porque sólo opera con dos elementos (ibid., pp. 96-96). En la p. 200 de esta misma obra explica que el esquema de «estado-regla» deja fuera la gran parte del comportamiento que es expresado en acciones espontáneas. Biológicamente, la vida no es mantenimiento del equilibrio, sino más bien mantenimiento de desequilibrios como sistema abierto. Como sabemos, todo sistema abierto presupone influencias diversas y complejas en las que la creatividad, en su sentido más amplio, es imprescindible. Los sistémicos — poco importa que nos refiramos a Rawls o a Luhmann- no pueden explicar la creatividad, que es un factor que, por alterar el estado de equilibrio, ha de ser visto como el máximo mal.

9 Hegel reprochó a estas filosofías el solipsismo sobre el que estaban construidas y explicó que: «Lo que yo siento solamente es mío, me pertenece a mí como individuo particular, pero como la lengua expresa siempre lo universal, yo no puedo expresar lo que es un sentimiento mío exclusivamente. Lo que no puede ser nombrado ni comunicado, es decir, las sensaciones y los sentimientos, no es lo que hay de más importante ni más real; es, por el contrario, lo más insignificante y lo menos verdadero. Cuando yo digo: lo individual, este individuo, aqui y abora, todas estas frases son universalidades, y bien que por todos y cada uno, aunque se trate de un aqui y ahora sensibles, se quieren designar cosas individuales, 
que en principio es incomunicable por irreductible. Cabalmente, Descartes hizo una filosofía de esencias puras de acuerdo con el sueño de la matemática universal ${ }^{10}$, en la que no había lugar para las existencias siempre concretas. Esto ha sido lo normal desde que se extendió la idea de la existencia de una morfología universal de las operaciones matemáticas, una pretendida universalidad que alcanzó también a las ciencias humanas. Pero tenemos derecho a preguntar que por qué motivo o motivos esta racionalidad es afirmada como objetiva o universal; parece que esto es una secuela de la filosofía cartesiana, patente especialmente en sus derivaciones más tardías, que se mueven en una especie de argumento ontológico que no alcanza solamente a Dios, sino, ante todo, a la universalidad del noúmeno racional en que se supone que consiste el universo al alcance nuestro, lo que implica además que el universo racional es transparente al hombre. Al apartarse este noúmeno del estudio individualizado de las cosas, se agotó en ser «razón» y esta razón se agotó, a su vez, en alguna racionalidad concreta.

El camino que emprendió Descartes se mostró más plenamente en el idealismo, ante todo en el kantiano ${ }^{11}$. Usualmente se dice que Kant destruyó la metafísica al distinguir entre el entendimiento (o Verstand), cargado de principios puros a priori, y los fenómenos suministrados por los sentidos. Pero esta doctrina la expuso en «La doctrina de los elementos», que forma la primera parte de la Crítica de la Razón Pura, mientras que en la segunda parte de esta obra, «La dialéctica trascendental», estableció un orden de ideas puro y subsistente por sí, que dispone de sus propias leyes para su desarrollo y que aparece como la realidad primera que ha de estudiar el filósofo. Los tres intereses de la razón - la existencia de un orden moral objetivo, la inmortalidad del alma y la existencia de Dios- ponen en marcha un

todas estas palabras designan lo general». Vid. G. W. F. HeGEL, Enzyklopädie der philosophischen Wissenschaften, Frankfurt am Main, Suhrkamp, 1970, $\$ 254$.

${ }^{10}$ Estas deducciones se componen de teoremas, y podemos preguntarnos si los pasos argumentativos que permiten avanzar teóricamente a tales teoremas tienen naturaleza lógica, geométrica, matemática, de utilidad o de conveniencia según el fin ya propuesto. Ningún autor de los siglos XVII y XVIII que yo conozca trató este tema. Se lo plantearon expresamente Peano y, más temáticamente, Frege. Aun así, no parece que haya acuerdo, y nuestros silogismos viven ahora en el mismo estado salvaje que hace siglos.

${ }^{11}$ KANT supuso, del mismo modo que Descartes, un noúmeno universal en el que participa el hombre, de forma que la totalidad racional está siempre adelantada a cada ser humano concreto. En su Crítica de la razón pura abordó en dos ocasiones el argumento ontológico. En A585 establece la necesidad de la unidad absoluta de las ideas — que sólo puede ser Dios - como fuente originaria de todas las posibilidades. Pero en A592 lo rechaza alegando que una idea no tiene por qué existir sólo porque la razón la necesite. Sus juicios son negativos durante varias páginas más. Finalmente, en A625 lo admite sencillamente, sin explicaciones. 
desarrollo ante todo físico-mecánico (no entenderíamos esta filosofía si prescindiéramos de las reglas de la mecánica) que forma la filosofía práctica, que es la vertiente de la filosofía que, según Kant, ostenta la primacía en la dirección del conocimiento humano ${ }^{12}$. Este mundo nouménico, que sólo existe cuando funciona, es el mundo en el que habita lo humano, y cada ser humano ha de ser deducido desde él, cosa que Kant afirma conseguir mediante el principio del entendimiento (Verstand) que él llamó la apercepción trascendental. No parece que Kant supiera bien qué quiere decir esta expresión, pero ha sido normal entre los filósofos usar términos extraños ante las dificultades que rompen el lenguaje consolidado.

La primacía la tuvo el bomo noumenon afirmado a priori, y la persona concreta apareció como un apéndice de aquel noúmeno, pero sin que estos filósofos explicaran la razón por la que la persona emerge como un ser libre, esto es, relativamente autónomo: la apercepción trascendental sólo permite entendernos como individuos y nuestra conciencia queda al margen de esta apercepción. ¿Puede existir una autoconciencia al margen de la conciencia moral? No, desde luego ${ }^{13}$. Pues parece que la persona es aquel ser que está sometido a leyes naturales y nouménicas que determinan su actuación, pero que trasciende a veces esas leyes mediante una autonomía que no puede ser explicada desde esas legalidades; esta autonomía no es la del género humano en su conjunto o la propia de cualquier moral positiva, sino la de los seres humanos concretos irreductibles a órdenes de legalidad previamente establecidos.

Es cierto que el momento histórico en el que vivía Kant había tasado sus posibilidades argumentativas: bajo la visión newtoniana del mundo, la naturaleza era el ámbito de la necesidad (o Notwendigkeit), es decir, de las leyes que se cumplen inexorablemente; por el contrario y dialécticamente, el mundo humano había de ser el mundo de la libertad o del arbitrio ${ }^{14}$. Pero Kant y los kantianos no explicaron cómo surge el arbitrio individual

12 En A840 escribe que: «Los fines esenciales no son todavía los supremos. Sólo uno de ellos (en una completa unidad sistemática de la razón) puede ser [...] Éste no es otro que el destino entero del hombre, y la filosofía relativa al mismo se llama moral. La superioridad de la filosofía moral frente a cualquier otra aspiración racional explica que también los antiguos siempre entendieron por filósofo, de modo superficial, al moralista». Vid. I. Kant, Crítica de la razón pura, trad. de P. Rivas, Madrid, Alfaguara, 1988.

13 Tomás de Aquino describía a la conciencia moral o al yo (los latinos no distinguían entre consciencia y conciencia como Cum alio scientia). Sobre este problema vid. mi estudio «Persona, Derecho, judicatura», en F. CARPINTERO y M. C. Londoño (coords.), El derecho a la justicia imparcial, Granada, Comares, 2012, pp. 1-40, disponible en la web franciscocarpintero.com.

${ }^{14}$ Es sintomático que estos filósofos, que historié en La Cabeza de Jano, usaran siem- 
desde el orden ideal a priori. No es que no lo explicaran; de hecho, sucedía más bien que sus axiomas les vedaban tal explicación. Kant entendió que la explicación de la realidad que proporcionó Newton era la ciencia definitiva, y ¿cuál puede ser el puesto del ser humano en el mundo de Newton? Del mismo modo que Dios, la persona quedaba fuera del mundo, y así como hablamos de un Deus ex machina, podríamos hablar de una Persona extra machinam.

Kant se había dejado llevar por la intuición básica de Rousseau, al que él llamaba el Newton del mundo moral. Rousseau no creía en la ley moral en el sentido corriente de la expresión, ni en la ley natural en el sentido más usual en el iluminismo. Es todo un problema determinar la forma como hemos de entender a Rousseau: ¿atendemos a su obra en gros o seguimos la lógica del Du contrat social? Si lo entendemos desde este último punto de vista, hay que reconocer que él presentó a unos individuos indiferentes unos a otros en el estado de naturaleza, que solamente a través de un nervio de su existencia social alcanzaban la eticidad o moralidad. Este nervio no podía ser la personalidad individual (ésta sería más bien en él el principio de toda injusticia) ${ }^{15}$, sino aquel interés verdaderamente común de la humanidad que llegamos a conocer despojando a los seres humanos de sus particularidades ${ }^{16}$. Las personas no eran reconocidas como tales, sino que únicamente componían esa materia bruta de la doctrina ética que le era imprescindible para componer su teoría de la sociedad. La síntesis a priori roussoniana adelantaba unos seres humanos que sólo tenían «sentido» desde la visión final del sistema ético propuesto, sin que las personas concretas fueran tenidas en cuenta en la génesis de lo justo. Es cierto que algunas obras suyas tienen un tinte más personalista, pero en el Du contrat social expuso bastante rotundamente este pensamiento, tal como destacó Jellinek polémicamente ${ }^{17}$.

pre el término Willkühr (arbitrio) y no el notablemente más complejo de Freibeit (libertad). Estudio disponible en la web franciscocarpintero.com.

${ }^{15}$ Los moderni habían insistido en la philautia (o amor a sí mismo) como el rasgo distintivo y orientador de las actuaciones individuales. Por tanto, todo lo que pusiera amistosamente - por así decir - en contacto a un hombre con otro no podía consistir en disposiciones o actuaciones personales (transidas de egoísmo por definición), sino en algún tipo de orden lógico o nouménico que supliera la falta de moralidad en las personalidades reales. Hobbes dio ejemplo de este tipo de argumentación al corregir al jus naturale a través de los laws of reason.

${ }_{16}$ Es significativo que Rousseau no aborde el tema de la diferencia hegeliana entre particularidad (o Besonderheit) y peculiaridad (o Einzelheit).

${ }_{17}$ Georg JeLLineK dedicó su obra Die Erklärung der Menschen- und Bürgerrechte, 3. ${ }^{a}$ ed., München-Leipzig, Duncker und Humbolt, 1927, a mantener esta tesis. Fue contestado en célebre polémica, pero lo cierto es que la dinámica de explicación de Rousseau llevaba hacia el Estado totalitario, como mostró el siglo Xx. 


\section{FUNCIONES SOCIALES Y CONSTRUCTOS LÓGICOS}

Ahora sería el momento de analizar, siquiera sea muy someramente, algunos nervios del desarrollo teórico de esos conjuntos teoremáticos, pues si a lo expuesto concretamente en estos libros lo podemos llamar contexto de presentación, al método seguido lo podemos designar como contexto de justificación; la tendencia a insertar contextos de justificación está reconocida desde antiguo ${ }^{18}$.

Efectivamente, si el lector de estas obras acepta el método, los elementos insilogizados en él le llevarán casi indefectiblemente a las conclusiones que le interesan al autor de la obra que leamos. Al fundarse ante todo en restricciones epistemológicas, lo presente es tomado, paradójicamente, como signo de ausencia y este estrechamiento del raciocinio que permitía llegar sin problemas hasta el final de la cadena axiomática, constituía la garantía de la calidad científica. Estas teorías trataban de componer estudios «redondos», como les gusta llamarlos a los editores. Estas ausencias tienen un sabor muy teórico-disciplinar, ya que se incluyen en teorías a partir de las cuales algunos crean frecuentemente una disciplina o asignatura académica que tiene como quicio excluir lo que, según sus autores, no hace al caso. Si mostramos una mariposa a un botánico y le preguntamos qué es lo que le enseñamos, este científico podría decir: «Es una margarita». «¿Por qué la llamas margarita si ves que es un insecto?». «Porque yo soy botánico». Éste es el caso, entre los teóricos de hoy, de Rawls, Apel o Habermas, a pesar de las diferencias más concretas entre ellos.

Funcionaron con lo que podríamos llamar el raciocinio-función, porque tomaron un dato de la vida real y, mediante razonamientos lógicos, lo pusieron al servicio de la función teórica de una realidad más amplia ya imagina-

${ }^{18}$ Gabriel BiEL, en la segunda mitad del siglo xv, distinguía limpiamente ambos contextos: «Tertium notandum: quod est duplex actus intellectus, aprehensivus et judicativus. Primus est respectu cuinscumque potentiae terminare actus potentiae cognitivae, sive sit complexum, vel incomplexum. Sic aprehendimus terminos propositionis, et ipsas propositiones, argumenta et syllogismos, demonstrationes: et universaliter omnia, quae respiciunt objective a potentia intellectiva. Actus judicativus est actus intellectus, quod assentit, vel dissentit propositioni verae, vel falsae: et illa est tantum respectu complexi propositionalis [...] intellectus habet duos actus scil. aprehensivum et judicativum. Et sunt separabilis, primus a secundo» (G. BIEL, Commentarii doctissimi in IV Sententiarum libros, Brixiae, Prologus, Quaestio Prima, 1574). Domingo de Soto, desde una posición filosófica general distinta, también distinguía ambos momentos y escribía: «Unde cum duae sint partes scientiae, ut rem intelligas, altera ut credas» (D. DE Soto, Dialecticam Aristotelis Commentarii, Salamanticae, Quaestio Prima super Prologum Porphyrii, 1580, p. 13). 
da y pretendidamente normativa o, al menos, benefactora. De este modo la función pretederminada se erigía en la guía de la investigación, y lo que más destaca en sus obras es la unidad subyacente que confiere - desde aquella función teórica — unidad, armonía y pureza al sistema; así creyeron estar construyendo un edificio científico, y desde entonces la pretensión sistemática se ha erigido en sinónimo de cientificidad o seriedad de las investigaciones ${ }^{19}$. Quisieron mirar más allá de cada sentido específico para comprenderlo en términos de su génesis necesaria y universal en cada sujeto y sacrificaron las especies a los géneros, entendieron que así construirían una ciencia de los elementos de la experiencia que, al margen de la función solitaria que ellos les asignaban, quedaban vacíos de contenido.

En este punto no hubo diferencias entre los fenomenistas como Hume o los idealistas como Fichte, pues ambos se nutrían de este mismo ambiente intelectual. La totalidad fue anticipada en ambos casos. Una vez introducida la totalidad, es ella la que domina en su unidad, pues el espíritu moderno no es capaz de concebir totalidades que no sean unitarias, y entonces se produce la tensión típica de esta totalidad que aspira a reintroducir en sí a los elementos aparentemente dispersos por las determinaciones que, de hecho, les resultan inexplicables.

\section{LA UNIDAD LÓGICA PUESTA POR EL MÉTODO}

Suponían una totalidad o conjunto operativo total ${ }^{20} \mathrm{y}$, en definitiva, una identidad de esta totalidad consigo misma conseguida mediante la representación paralógica de la infinidad y de la infinitud ${ }^{21}$. Las tesis de Gabriel Vázquez, Luis de Molina y Francisco Suárez relativas a la identi-

19 W. Tr. Krug definía el sistema como: «So versteht man unter eine nach setzen Regeln geordnete und auf ein bestimmtes Ziel gerichtete Lebensweise. Jene Regeln können man entweder praktische (Rechts- und Tugendgesetze) oder bloß pragmatische (Klugheitsregeln) sein, daß also entweder ein sittliches oder ein sinnliches sein, so daß dort die Vernunft, hier der Verstand vorwaltet» (W. Tr. KRUG, Allgemeines Handwörterbuch der philosophischen Wissenschaften nebst ihrer Literatur und Geschichte, vol. V, 2. ${ }^{\text {a }}$ ed., Leipzig, Brockhaus, 1832, p. 352).

${ }^{20}$ Diderot explicitaba con brevedad digna de agradecimiento lo que otros muchos ilustrados exponían tras muchas páginas: «La independencia absoluta de un solo hecho es incompatible con la idea de totalidad, y sin la idea de totalidad ya no hay filosofía» (D. DiDEROT, Sobre la interpretación de la naturaleza, trad. de J. Mateos, Barcelona, Anthropos, 1992, \XI, p. 23).

${ }^{21}$ Los medievales no entendían que el espacio fuera uniforme. Tomás de Aquino establecía una adecuación entre la cosa y el espacio que ésta había de ocupar, de modo que, ante todo, el locus había de ser adecuado (dignus) a la cosa de que se trataba. Vid. T. DE AQuino, In octo libros Physicorum Aristotelis Expositio, Torino-Roma, Marietti, 1995, $\$ 446$. 
dad de cada sustancia consigo misma fueron traspasadas a la idea misma de espacio como conjunto uniforme y siempre idéntico a sí mismo de extensión en el que están situados los cuerpos; desecharon la tesis medieval que entendía que el espacio tiene dimensiones distintas ${ }^{22}$. Como nos indica Gent, idearon, de la mano de Suárez, un espacio modal libre de formas $^{23}$, y ya tenían la base para el espacio humano que dominaba sus construcciones: unos individuos en un status naturae que desconocía la pluralidad de cosas que nos muestran las vivencias de la cotidianidad de la vida jurídica; en él sólo existían individuos con pasiones que podían ser fomentadas o rechazadas. La pluralidad ontológica representada por las personas y las cosas distintas fue declarada ab initio sin valor.

Esta singular metafísica moderna - si por tal entendemos ahora el conjunto de tesis necesariamente operativas en teorías que dicen no poseer ningún presupuesto teórico que no proceda desde la observación- decidió el futuro de la geometría y de la lógica, y el mos geometricus extendió esta uniformidad también a las ciencias humanas. Era una actitud observacional muy singular que se dictaba a sí misma «lo que» había que examinar y lo que no era lícito ni siquiera mirar.

Como ya indicaba al inicio de este estudio, estamos ante una anticipación en la que los factores aparentemente posteriores determinaban el movimiento de los elementos anteriores, y esta anticipación introducía la unidad total, sistemática, que realmente no era tanto un resultado como la regla maestra: la unidad reside en la concordancia que está creada por un plano de validez o justificación. El conocimiento se identifica con el juicio, que incorpora lo particular con la totalidad del sistema. Todo pensamiento que no tienda al sistema carece de dirección o es autoritario por arbitrario ${ }^{24}$. Los conceptos podían tener de hecho valor universal porque suponían implícitamente que la materia era única y el movimiento era igualmente único: la identidad de la

${ }_{22}$ Tomás de Aquino explicaba: «Quod locus sit unum de quattuor; scil. vel materia, vel forma, vel aliquod spatium inter extrema continentis; vel si nullum spatium est inter extrema continentis, quod habeat aliquas dimensiones, praeter magnitudinem corporis quod ponitur infra corpus continens, oportebit dicere quartum, scilicet quod habeat aliquas dimensiones» (T. DE Aquino, In octo libros Physicorum.., op. cit., $\mathbb{\$} 456$ ). Poco después, en el $\$ 461$, rechaza la noción de espacio como un continuum indefinido.

${ }^{23}$ Un «formfreie Zeitmodus». Esta terminología la usa Werner Gent en Die Philosophie des Raumes und der Zeit, vol. I, Bonn, Verlag von Friedrich Cohen, 1926, p. 318.

${ }^{24}$ Vid. M. Horkheimer y T. Adorno, Dialéctica del Iluminismo, trad. de H. A. Murena, Buenos Aires, Editorial Sudamericana, 1987, pp. 102-103. Diderot escribía expresivamente que: «L'indépendance absolue d'un seul fait est incompatible avec l'idée de tout; et sans l'idée de tout, plus de philosophie» (D. DiDEROT, Pensées sur l'interprétation de la nature, Barcelona, Anthropos, 1992, \$XI, p. 22). 
naturaleza (¿de la materia?) consigo misma garantizaba la irrelevancia de la pluralidad de las formas. La instantaneidad en la percepción y la causalidad eficiente aparecieron como las categorías máximamente evidentes.

Apareció así un marco que operaba continuadamente como contexto de justificación, constituido también por el sentimiento de la unidad de todo lo natural en sentido estricto ${ }^{25}$, en su constitución y en su dinámica. Es el problema eterno de la representación del espacio como marco posibilitador de la propia teoría, cuando no se supera la simple imaginación. Pero ahora, la unidad intelectual exigida por el espíritu del sistema hacía que coincidieran el espacio que tienen en cuenta las ciencias naturales y el espacio lógico o «espacio humano». Hegel lo indicaba claramente a propósito del materialismo de Locke: «Allí donde el pensamiento es algo concreto por naturaleza, donde el pensamiento y lo general aparecen identificados con lo extenso» ${ }^{26}$. Helvétius había expuesto antes esta misma tesis con la aparente claridad habitual de un empirista: «Entender por la palabra naturaleza el encadenamiento eterno y universal que vincula conjuntamente todos los acontecimientos del mundo, en el que la idea misma de azar se encuentra comprendida» ${ }^{27}$. El materialismo estaba sustituyendo a la intuición de las formas diversas por la imaginación de la materia en la conciencia objetiva ${ }^{28}$.

Y del mismo modo que los conceptos geométricos o mecánicos, los pilares de la nueva racionalidad eran descarnados y ahistóricos, susceptibles de ser utilizados igualmente en la física como en la ética sin cambiar sus propiedades. Precisamente esta única operatividad de los conceptos

\footnotetext{
${ }^{25}$ Según Condorcet, el esquema general del mundo psicológico del ser humano es tan necesario por insertarse tan exactamente en el único esquema existente, que debe ser llamado «métaphysique». Vid. N. DE CONDORCET, Esquisse d'un tableau historique des progrès de l'esprit bumain, Paris, Flammarion, 1988, p. 80. En cambio, el lenguaje que nos une a los hombres es cosa lograda «par des moyens artificiels» (ibid., p. 79).

${ }^{26}$ G. W. F. HegeL, Lecciones sobre la historia de la filosofía, trad. de W. Roces, vol. III, México, FCE, 1985, p. 329. Christian Wolff lo explicaba en términos omnicomprehensivos y aun rudimentarios: «La perfección de una cosa en general reside en la concordancia (Uebereinstimmung) de lo múltiple en uno o de varios que están separados entre sí en una sola cosa. Esta concordancia es la determinación (Bestimmung) a través de la cual todo lo que es cierto tiene un destino común» (C. WolfF, Grundsätze des Natur-und Völkerrechts worin aller Verbindlichkeiten und alle Rechte aus der Natur des Menschen in einem beständigen Zusammenhänge hergeleiten werden, libro I, $\$ 9$, Hallae im Magdeburgischen, 1754. El título del libro es ya casi tan significativo en sí mismo como la cita expuesta).

27 C.-A. Helvétius, De l'Esprit, Paris, Durand Libraire, 1758, p. 326.

${ }^{28}$ Saumells define a la conciencia objetiva como: «El ámbito de una cierta forma de presencia propia de los objetos en tanto que están destinados a su conocimiento» (R. SAUMELLS, La geometría euclídea como teoría del conocimiento, Madrid, Rialp, 1970, p. 34). Descartes prefería la palabra «imagination». Vid. R. DesCARTES, «Seconde méditation», en Euvres et lettres, Paris, Gallimard, 1953, p. 280.
} 
básicos, que los volvía comunes a todas las ciencias, parecía ser el garante de la cientificidad que reclamaban para sí las ciencias humanas ${ }^{29}$. La conciencia, al convertirse en el objeto de estudio de sí misma, anticipaba sus propias leyes, y el filósofo, al abandonar el criterio genérico del subjecta materia, explicó que estas leyes eran comunes para todos los sectores de la vida humana. El empirismo hubiera debido dejar a la conciencia nadar en los propios hechos entregándose a ellos por entero, pero el amor propio y los intereses obligaron a ser más positivistas que empiristas, normando a los hechos según leyes, pero en nombre de su simple descripción. Helvétius habló del Esprit, pero este mismo título de su libro es equívoco, porque nunca renunciaron al Esprit para abandonarse a los hechos.

Los conceptos devinieron así universales, aunque no en el sentido antiguo, platónico o aristotélico, sino en el propiamente moderno de necesarios ${ }^{30}$, ya que estos conceptos se alimentaban — por así decir- desde una sola realidad. Los modernos creían en la naturaleza una o unitaria, cuyo conjunto fue llamado Nisus, Trabant o Weltall, y cuya nota fundamental a los fines científicos era la identidad de sí misma en todos sus momentos y manifestaciones ${ }^{31}$.

\section{EL PLANO DE JUSTIFICACIÓN: LA RAZÓN METÓDICA Y LOS MÉTODOS CONCRETOS}

Gracias a las restricciones impuestas por el método, unificaron lo que suele ser llamado usualmente el contexto de presentación y el contexto de

${ }^{29}$ El marqués de Condorcet explicaba: «Ainsi, l'analyse de nos sentiments nous fait découvrir, dans le développement de notre faculté d'éprowver du plaisir et de la douleur, l'origine de nos idées morales, le fondement des vérités générales qui, résultant de ces idées, déterminent les lois immuables, nécessaires du juste et de l'injuste; enfin, les motifs d'y conformer notre conduite, puisés dans la nature même de notre sensibilité, dans ce qu'on pourrait appeler, en quelque sorte, notre constitution morale. Cette même méthode devint en quelque sorte un instrument universel; on apprit à l'employer pour perfectionner celle des sciences physiques, pour en éclaircir les principes, pour en apprécier les prewves; on l'étendit à l'examen des faits, aux règles du goût» (N. DE CONDORCET, Esquisse d'un tableau bistorique.., op. cit., p. 223).

${ }_{30}$ Priestley, que, como es lógico, no podía admitir conceptos universales, admitía, sin embargo, la validez incondicionada de la ley de causalidad derivándola desde la constancy entre la causa y el efecto. Vid. J. PriestLey, The doctrine of philosophical necessity, London, J. Johnson, 1777, p. 11.

${ }^{31} \mathrm{La}$ modernidad en el Derecho se sirvió de varias nociones de naturaleza, dos fundamentalmente: una, la del individuo aislado y autónomo en el status naturae (éste fue el caso de Pufendorf, Gundling, Koehler, etc.), y la otra, la representación mental del todo universal regido por un único movimiento que reelabora incesantemente la protomateria o las sensaciones (fue el caso de Condorcet, d'Holbach o Helvétius). 
justificación, y la falta de matización les llevó a perder de vista sus diferencias. El contexto de presentación sería el discurso expuesto según los condicionantes de la cultura (geométrica, matemática, física, ética, etc.) en la que cada época expone sus aportaciones, incluyendo el momento metódi$\mathrm{co}^{32}$. El contexto de justificación estaría compuesto por los presupuestos y las operaciones racionales por las que los científicos sitúan un ámbito más amplio - aunque en realidad estos métodos se definían más bien por sus restricciones- para hacer posible su método según, fundamentalmente, una representación de los objetos en el espacio, y así alegan que lo expuesto en tal discurso es objetivo, natural, aceptable, etc., y lo prolongan según argumentos de lógica o conveniencia. Como es lógico, excluimos los casos groseros en los que el problema viene constituido precisamente por los términos mismos de la posición del problema.

No quisieron o no pudieron entender que, aunque partían desde un esquema previo, usaban representaciones simplificadoras que no podían ser justificadas desde los conceptos necesarios puestos en ese esquema, ni el esquema justificaba los conceptos que el científico usaba. En tales casos se suele hablar de demostración circular, porque se supone que el éxito de una teoría suplirá su falta de fundamentos teóricos. Pero si recurrimos a las explicaciones del positivismo jurídico más clásico, ¿podemos hablar hoy del éxito social de Bergbohm, Kelsen, Bobbio o Hart? Si por éxito entendemos su aceptación inmediata, en su momento, por un sector de la cultura, sí. Si por éxito entendemos una explicación que permanece serena, aportando claridad, en medio de las vicisitudes de la historia, no. Con razón el positivismo clásico ha sido sustituido por el positivismo jurídico incluyente, que no conserva de «positivismo» casi nada más allá de su título ${ }^{33}$.

En realidad, estos autores aportaron no tanto fundamentos de sus teorías como referentes para ellas, y el referente más usado fue el de la validez. ¿Qué quedaría de la ética moderna y contemporánea si prescindiéramos de las exigencias, tan débiles, de la doctrina de la validez? La validez lo uniforma todo en el plano humano y político, porque la misma naturaleza tiene un decreto para reparar una carretera y otro para comprar

32 Éste ha sido un tema recurrente en la historia de la filosofía. El mismo Descartes lo expresaba con precisión: «Car l'action de la pensée par laquelle on croit une chose, étant celle par laquelle on connait qu'on le croit, elles sont souvent l'une sans l'autre» (D. DESCARTES, Discours de la méthode, 3. ${ }^{a}$ parte, Paris, Gallimard, 1953, p. 141).

33 Vid. Pedro Serna, Filosofía del Derecho y paradigmas epistemológicos. De la crisis del positivismo a las teorías de la argumentación jurídica y sus problemas, México, Porrúa, 2006, p. 54. 
armamento militar. La referencia común a un punto de atribución ideal les hacía representarse, como existentes o válidas, conductas y exigencias científicas que no eran diversas, según ellos, porque tenían el mismo fundamento genético.

La conciencia humana, que tantas construcciones soporta pacientemente, determina frecuentemente, por ella misma, el plano de la justificación en que consiste el test de la validez. Cuestión distinta es el plano de la representación o de las representaciones. El contexto de justificación es siempre único en estas teorías que hacen suya alguna categoría de la validez; en cambio, lo que podríamos llamar el plano de representación es notablemente más complejo y no se atreve a dictar un único contexto validador.

Veamos. Si sigo un ejemplo que suelen proporcionar los geómetras, imagino que tengo ante mí la almohadilla en la que la costurera clava los alfileres; yo podría clavar los alfileres en tal almohadilla según distintos planos observables desde distintos escorzos, y lo que resulte así no será normalmente una figura geométrica concreta (si quiero, puedo construir un pentágono con los alfileres, pero a condición de decidir o construir yo el plano concreto). Entonces puedo hablar de un plano de presentación: el pentágono construido, y de un plano de justificación, que es el plano que he elegido según mis intereses (está llegando el momento en el que es preferible prescindir de la expresión de plano de justificación y usar la de plano de objetividad y contexto de representación, porque el momento de la validez siempre es único y opera monótonamente, mientras que los contextos de representación operan según cada cosa, de modo que cada realidad es conocida en medida distinta). Obviamente, el ámbito de que garantiza la objetividad no aparece, o no es percibido, ya que queda más allá del ámbito de presentación.

Esto es evidente desde el punto de vista de la construcción geométrica, pero pasó desapercibido en las teorías ético-jurídicas ilustradas: ¿qué quedaría de ellas si distinguiéramos el plano de la justificación de los planos de la presentación que expuso cada autor? Es cierto que una ciencia se constituye por la aplicación de un método, pero si el método cumple ante todo una función excluyente, permanecemos en los problemas denunciados; es una actitud pobre hacerse uno digno a costa de denigrar a los otros. Parece que un método ha de hacerse incluyente, incluso soportando las contradicciones en su interior, y en este caso, las contradicciones nos hablan tanto de la amplitud de espíritu del científico que las admite como de las insuficiencias de su actitud metódica. Si no reconocemos este hecho es de temer que volvamos una y otra vez al eterno problema del científico que declara que una mariposa es una margarita porque él es botánico. 
Además, queda siempre en el aire el problema de la combinación adecuada del plano de la presentación con el plano de la objetividad, que funciona habitualmente como contexto de justificación, porque nuestras ciencias no han sido tanto ciencias «de» como ciencias «como». Los problemas suscitados desde el contexto de justificación son los que han hecho saltar históricamente los contextos presentados, ya que llega un momento en el que las aporías que encuentra la comunidad científica que sigue un mismo criterio de justificación hacen cuestionar las limitaciones primeras que constituyen el método. No fue un geómetra genial el que destronó a Euclides, como sustituyendo la teoría del griego por la suya propia, fueron las operaciones matemáticas propias del momento de la explicación y justificación las que, agobiadas por las aporías excesivas que resultaban desde los postulados euclidianos ${ }^{34}$, los pusieron en cuestión. Esto lo hizo Descartes.

Ya que distinguimos dos contextos de lo científico, hemos de preguntarnos sobre lo más elemental, esto es, sobre si las estructuras de nuestra razón se pueden cuestionar ellas a sí mismas y si mediante ulteriores análisis y síntesis pueden llegar a un resultado cualitativamente distinto de lo que ya sabíamos en el punto de partida. Históricamente, este tipo de cuestionamientos ha envuelto dos temas distintos que los reconocemos, por ejemplo, en Descartes. Uno de ellos es si tales análisis nos pueden llevar a ampliar el momento inicial del conocimiento. Podemos responder que sí, ya que vemos cómo la mecánica y la física cartesiana representaron un avance serio sobre la ciencia anterior, aunque mostrando una cierta continuidad con ella, y los modelos científicos anteriores funcionan - queramos o no- como axiomas o como instrumentos para alcanzar propuestas nuevas ${ }^{35}$. No en vano denuncian los físicos que los instrumentos de obser-

34 Ya Alejandro de Hales (o de Alés), en el siglo XIII, negaba la adecuación de la geometría a la matemática y escribía: «Similiter de Geometria; non enim videtur, quod sensibiles lineae sunt tales, quales sunt illae, de quibus determinati cum enim omnis scientia sit circa rerum, et multa, quae dicit Geometra, non sunt vera, in sensibilis lineis, videtur quod aliae sunt lineae Geometriae, alia sensibiles, et aliae figurae ambarum: multo enim rectum de numero sensibilium, nec rotundum est tale, quale est illud, de quo determinat Geometra, quia non babent proprietates illius: circulus enim secundum Geometram tangit planum un puncto; circum autem sensibile non tangit res, hoc est planum in puncto; ita quod aliae sunt proprietates verum Mathematicarum, et aliae et rerum sensibilium» (A. DE HALES, In Duodecim Aristotelis Metaphysicae Libros dilucidissima Expositio, Venetiis, Simonem Galignanum de Karera, 1572, p. 60-D; el tema ya lo había introducido en la p. 8-A). La incompatibilidad entre la geometría y las matemáticas no representaban problema para los medievales, porque ellos - gracias a su mayor elasticidad de espíritu - entendían que cada cosa exige su propio método de conocimiento, y que sólo se deja conocer en la medida en que de hecho pueda ser conocida por el hombre.

35 Descartes declaró que: «Siempre que se deduce un objeto determinado y desconocido de otro ya conocido anteriormente, no por ello se encuentra un nuevo género del ser. 
vación que permiten cuestionar a Euclides han sido construidos según la geometría euclídea ${ }^{36}$.

El otro es si el cuestionamiento inicial no nos llevará a un tipo de racionalidad distinta a la reconocida anteriormente, la que nos permitió iniciar el estudio científico propio del método moderno. Contestar a esta segunda pregunta es un tema más difícil porque, en honor a la verdad, hay que decir que nadie ha sabido explicar en qué consiste una racionalidad diferente de la anterior. Porque lo justificado y la justificación se presentan tan unidos que no admiten - al menos efectivamente- disociaciones. Sucede que uno es el momento del espíritu metódico, que es el de la razón en su plenitud cuando busca en su entorno, y otro es el momento de los resultados científicos que obtenemos aplicando un método. Aquel primer momento es más amplio y fundante, y este carácter lo reconoce cualquier investigador cuando contrasta su actitud personal que le lleva a inquirir sobre los resultados obtenidos a través de un método: siempre permanece la sensación de insatisfacción, ya que el método suele mostrar ante todo su aspecto deficiente cuando es contrastado con la realidad más amplia, que podemos llamar la razón metódica demostrativa. Poco importa que hablemos de ciencias naturales o de humanidades; cuando el autor ha de corregir las pruebas de imprenta de lo que él ya ha escrito, normalmente trata de introducir correcciones no porque se haya equivocado en algún dato concreto, sino porque es alcanzado por la tensión entre el espíritu metódico y lo que le ha permitido obtener el método que él ha seguido.

\section{SERVIDUMBRES DEL ESPÍRITU GEOMÉTRICO}

La posición de un solo plano de justificación les permitió elaborar constructos que se han expresado normalmente en libros extensos. Ellos fueron —según el lema medieval — desde el punto a la línea, de ésta a la figura, desde la figura a la extensión. Fue Christian Wolff quien mejor expuso este proceder. En su tratado sobre el «Menschliches Thun und Lassen» reco-

Existe solamente una extensión de todo nuestro conocimiento que nos hace comprender, de una manera u otra, que el objeto buscado participa de la naturaleza de los que nos han sido dados en la proposición» (D. Descartes, Regulae ad directionem ingenii, trad. de F. de P. Samaranch, Buenos Aires, Aguilar, 1981, p. 119).

${ }^{36}$ Gonseth denunciaba que es paradójico que poniendo en luz las garantías reales del privilegio de lo euclídeo, demos una oportunidad a lo no-euclídeo. Vid. F. GONSETH, La géometrie et le problème de l'espace, vol. VI, Paris-Neuchâtel, Dunond Éditeur-Éditions du Griffon, 1955, p. 519. 
nocemos los pasos de este mos geometricus de forma prácticamente táctil, tangible ${ }^{37}$. Podemos hablar de mos geometricus para referirnos a la filosofía práctica porque los geómetras definen a una figura por una sola de sus propiedades, y normalmente suelen alegar que por la propiedad más sencilla.

Pero ésta es una argumentación demasiado imprecisa. La respuesta más aproximada sería la siguiente: la propiedad elegida es aquella que suministra un procedimiento de construcción ${ }^{38}$. Porque en este contexto construir es sinónimo de configurar, como cuando describimos aparentemente una circunferencia por la igualdad de los radios o por un radio que gira. Los integrantes de la modernidad eligieron aquella propiedad humana que de la manera más directa e inmediata se refería a la forma constructiva de la sociedad política (sólo la sociedad política, porque sus restricciones les vedaban considerar los otros tipos de sociedad en las que vivimos los hombres). Así, la razón se sometía a ella misma, a las leyes que se entendían entonces como científicas o psicológicas $^{39}$, porque la geometría era considerada el initium y el fundamentum de toda ciencia, y la razón aplicada a la sociedad se construía a sí misma según una de sus propiedades aparentemente esenciales. No servía el talante de Descartes, cuyo método era aún demasiado dependiente de intuiciones en la razón según sus pretendidos contenidos innatos.

La verdadera cuestión sería: ¿cómo llegó a formarse y a extenderse generalizadamente este nuevo sentido común que hacía posibles tantas cosas al mismo tiempo que descalificaba otras con toda rotundidad? Si reitero algo de lo ya expuesto, vemos que para resolver esta cuestión, la Ilustración entendió que bastaba situar al ser humano en el contexto que le correspondía en el Todo Universal (Trabant). La ciencia sobre el hombre que inauguran Hobbes, Locke, Thomasius o d'Holbach es ante todo intuitiva: basta con dejar que el espíritu ${ }^{40}$ se abandone a la plenitud de los hechos y se regule incesantemente por ellos, porque el hombre no es más que un sector del todo universal. No hay dualidad entre sujeto cognoscente y objeto conocido; ambos son la misma realidad, aunque el Esprit huma-

37 Pero este constructivismo geométrico no fue creación moderna, estuvo presente en las obras de bastantes filósofos de la Antigüedad y de la Baja Edad Media. Hobbes fue el primero, en el segundo milenio, en ser lo suficientemente desvergonzado para elevar a un plano único lo que hasta entonces no había sido sino un momento del conocimiento.

38 Vid. R. SAumells, La geometría euclídea..., op. cit., p. 62.

39 Ayer indica que, a mediados del siglo XVIII, aún no se había acotado lo que era científico, ni siquiera existía este término. Hume pensó estar haciendo psicología. Vid. A. J. AYER, Los problemas centrales de la filosofía, trad. de R. Fernández González, Madrid, Alianza, 1984, p. 35.

${ }^{40}$ El espíritu solamente puede ser entendido en el sentido que lo hace HeLvétius en De l'Esprit, esto es, como conciencia de la necesidad. 
no permita la autoconsciencia. Cuando este modo de pensar fue traspasado a las ciencias jurídicas y políticas, sus nuevos teóricos afirmaron que estas ciencias descansaban en una identidad entre sujeto y objeto, en la identificación entre razón teórica y razón práctica, y es precisamente esta implicación idéntica la que permite, como connaturalmente, que el sujeto llegue a su plenitud en su conocimiento y adecuación a lo que es y hay. Era un círculo mágico porque no estudiaba ni describía: la conciencia de la identidad de toda la realidad con ella misma actuaba continuadamente como contexto de justificación, y como este plano justificador componía la misma realidad con lo expuesto o justificado, lo uno se explicaba y garantizaba por lo otro; una argumentación retóricamente efectista.

Se trataba, en realidad, de una presentación mítica, pues el mito se justifica por lo que presenta: lo que se ve en el mito, se explica en él. Es un proceso similar al de la geometría: el círculo se forma por el giro de un radio, y no hay interrogante anterior ni ulterior sobre esta construcción. La conciencia medieval y moderna percibió esta analiticidad, y captó pronto que las figuras geométricas no se prestaban a explicaciones matemáticas; de ahí las denuncias de Alejandro de Alés, ya en el siglo XIII, y de ahí también la desconfianza de Descartes frente a los datos proporcionados por los sentidos. Todas las denuncias, sin excepción, que hace en su Discurso del Método se refieren a las falacias a que llevan las explicaciones racionales de los constructos geométricos. Es obvio que desconfiaba ante todo de los datos proporcionados por la vista.

La intuición figurativa estaba clara en el plano imaginativo, llamado por algunos geómetras actuales la conciencia objetiva, que es ese espacio ante todo visual e imaginado que nos permite representarnos abstractamente las figuras geométricas, y desde ahí nació la nueva filosofía; sólo faltaba trasladarla al terreno práctico. Esta última empresa no les planteaba dificultades; es propio del pensamiento simplista ver la vida como la aplicación clara de una regla a un estado de cosas claro y determinado. Porque el plano de la objetividad inconscientemente asumido presiona a las conciencias con tal fuerza que no son conscientes de haber elegido ellas su propia justificación, esto es, sus propias reglas metódicas, ni de estar justificándose a sí mismas al mismo tiempo que presentan su objeto construido de acuerdo con ellas. No tienen en cuenta la advertencia tomista que indica que Illud enim quod mensuratur, non videtur esse aliud quam mensura ${ }^{41}$, esto es, que la unidad de medida es eso mismo que ha de

${ }^{41}$ T. DE Aquino, In octo libros Physicorum.., op. cit., $\mathbb{} 636$. 
ser medido. Una vez que la ciencia ha quedado identificada con el objeto que considera, es el propio objeto el que queda diluido en la ciencia, y ahora todo el tema consiste en encontrar las reglas que dirijan la constitución de la ciencia manipulando a sus objetos. Ya indicaba que el empirismo geometrizante no ha sido coherente con sus postulados, porque no se deja llevar apaciblemente por los hechos que se dan y que aparentemente sólo estudia.

Siguiendo este mismo camino, algunos investigadores de la segunda mitad del siglo Xx han renovado la tendencia moderna de ofrecernos constructos unitarios y simplificados. La palabra constructo no tiene un estatuto científico claro y uniformemente admitido, y es procedente explicar qué entendemos por tal cosa. De acuerdo con el espíritu del Círculo de Viena, el constructo consistiría en tomar un número de conceptos fundamentales proporcionados por la misma observación — pues el empirismo se autopresentó como la explicación científica que no debe nada a nadie- para derivar desde ellos los demás conceptos según un desarrollo teoremático que fue llamado un sistema. Se trata de una construcción en la que los términos introducidos son definidos por términos previamente usados en el sistema: el uso de los primeros términos justifica la operatividad de los factores posteriores. De este modo, el constructo sería una teoría al margen de la entropía inevitable ${ }^{42}$, ya que tendría doble dirección: podríamos ir desde los axiomas primeros a los desarrollos posteriores o desde los conceptos implicados en estos desarrollos a los axiomas primeros, pues la intimidad del constructo reside en el construir o en el reducir, siempre construyendo gracias a reglas de traducción que proporcionan las funciones proposicionales necesarias, para ir desde aquellos axiomas a estos segundos conceptos, y desde estos conceptos finales a aquellos axiomas. Es una forma de construcción simplemente fenoménica y binómica que no admite la inferencia de entidades en el conocimiento, y que trata de reemplazar las entidades inferidas de hecho por construcciones. De acuerdo con este planteamiento meramente funcionalista, una «entidad» existe o es demostrable (expresiones sinónimas en este contexto) solamente cuando se puede proporcionar

${ }^{42}$ Desde una filosofía o teoría de la ciencia materialista no es posible dejar de lado a la entropía. Tirso de Andrés indica que: «Sabemos también que, frente al orden, la indeterminación intrínseca de la materia siempre permanece como una amenaza, como una tendencia al desorden, perpetuamente inclinada hacia el desbarajuste entrópico. La materia no lleva por sí misma a ningún progreso automático, sino a la muerte térmica del universo, a la entropía máxima del estado de equilibrio definitivo. Ése es todo el posible progreso material; ése es el cielo al que puede aspirar quien quiera ser sólo materialista» (T. DE ANDRÉs, Homo «cybersapiens». La inteligencia artificial y la bumana, Pamplona, Eunsa, 2002, p. 210). 
una regla o técnica para su construcción ${ }^{43}$. Una regla que -es ocioso repetirlo- ha de operar ya en el interior del sistema.

El método científico moderno mantuvo que solamente podemos conocer relaciones entre los hechos y nosotros, todos en el plano de los fenómenos. Locke, tras los pasos de Hobbes ${ }^{44}$, había dado una cierta forma literaria a esta pretensión y Hume, influido decisivamente por esta exigencia epistemológica newtoniana, declaró la incognoscibilidad de las «cosas» o sustancias. El problema estuvo en que Newton presentó la ley de la gravitación universal, por ejemplo, como un hecho, algo que conocemos sin poder explicar sus causas últimas, y esta asumida limitación del método científico hizo que David Hume llevara hasta sus últimas consecuencias la discontinuidad entre los datos de la sensibilidad, siempre fenoménicos, y por ello sin explicación ulterior desde ellos mis-

${ }^{43}$ La categoría del constructo provino desde la geometría: la poca fiabilidad de la geometría de Euclides - tal como se mostraba ante todo en los fallos de las explicaciones matemáticas de las líneas paralelas - determinó la desconfianza ante los datos suministrados por las intuiciones de la vista y, por ende, por todas las intuiciones provenientes de la sensibilidad. Como Descartes exigió confiar solamente en la demostración matemática, no le quedó más cauce para conocer que el deductivismo matemático realizado desde los axiomas innatos en el hombre. Este reemplazo del mundo de los sentidos por los razonamientos se vio reforzado por el sensismo y fenomenismo de Hobbes y su escuela. Cabalmente, todo empirismo no reconoce otro modo de ofrecer realidades acabadas al hombre, al margen de lo construido lógico-matemáticamente. Es bien sabido que el concepto de lo no-construido se les escapaba a los ilustrados.

Hoy seguimos en manos de esta forma de proceder según constructos, pues ¿qué le impide, por ejemplo a Rawls, reconocer que todos los hombres tienen derecho a una vida digna? Éste es un dato que lo proporciona hoy la experiencia social más elemental, y no debiera ser el punto final de un razonamiento, sino su base de partida. Pero un cierto prestigio académico exige, aún hoy, ser razonablemente materialista y empirista, y Rawls — según esta doble exigencia - nos propuso un largo y simplista razonamiento constructivista que parte desde unos individuos egoístas e iguales. Desde luego, estas exigencias del egoísmo individual son bastante menos «evidentes» (incluso desde un punto de vista estrictamente empirista) que el derecho de todos los seres humanos a un trabajo digno. Lo que nos confirma en la idea de que el problema sempiterno de los empirismos consiste en que son poco empiristas.

Además, aquella desconfianza ante los datos de los sentidos, que daba lugar a las actitudes constructivistas, debiera quedar en su lugar, esto es, para explicar problemas de la geometría y de la física teórica. Tenemos un derecho justificado a desconfiar de la evidencia sensible en lo que se refiere a las líneas rectas (¿podemos seguir hablando de líneas rectas después de Maxwell?), a las líneas paralelas y a la simultaneidad, entre otros datos. Pero los problemas de la intuición de los objetos en el espacio no se relacionan en nada con los problemas de la intuición de la cualidad moral de las acciones, como explicó KANT minuciosamente en Crítica de la razón pura, A43-A44.

44 Priestley, por ejemplo, nos indica que: «I am rather surprised that Mr. Locke, who seems to have so much indebted to Mr. Hobbes for the clear view that he has given us of several principles of human nature...» (J. PRIESTLEY, The doctrine of philosophical..., op. cit., p. xxix). 
mos, y que negara la validez de las proposiciones que afirmaban la existencia continuada de los cuerpos al margen de cada sensación concreta $^{45}$. Por supuesto, negó que hubiera de existir alguna correspondencia $a$ priori, o necesaria, entre las leyes de nuestro pensamiento y las leyes que muestran los fenómenos.

Este estilo metódico estaba basado en un modo de sentir que entendió que solamente hemos de tener en cuenta el protoelemento sensación que, reelaborado y transformado por la materia gris del cerebro, daba lugar al único conocimiento posible, y que viene a ser como la identidad de las cosas - más bien del movimiento- consigo mismo. Kant quiso mediar entre las abusivas posibilidades de la metafísica wolffiana en la que él se había formado y las excesivamente pocas posibilidades del empirismo inglés que tenía ante él. En el momento de explicar la geometría - y otros temas, pero siempre bajo el patrón de la geometría- estableció la existencia objetiva de sus categorías puras a priori del entendimiento (Verstand) humano. El conocimiento se explicaría desde sí mismo, pero distinguiendo como linealmente: a la izquierda, los datos de la sensibilidad, y a la derecha, los principios del entendimiento. En el centro del proceso estaría el psiquismo humano, que produce la síntesis trascendental entre aquellos fenómenos y estos principios ${ }^{46}$. Si abandonamos este esquema geométrico, que parece calcado de la recta numérica que proponen los matemáticos, poco quedaría de la capacidad pedagógica de Kant.

${ }^{45}$ Esta coincidencia es especialmente perceptible, a modo de axioma o principio básico, en la epistemología de Hume, quien, por lo demás, lo da por evidente, sin que se preocupe en aludir a por qué la sensación «instantánea» ha de constituir el fundamento de la ciencia. Locke había puesto los fundamentos argumentativos de tal exigencia cuando, al explicar qué es la identidad de un cuerpo consigo mismo, escribía: «When considering any thing as existing at any determinate time and place, we compare it with itself existing at another time, and therefore form the ideas of identity and diversity. When we see anything to be in any place in any instant of time, we are sure (be it what it will) that it is that very thing, and not another, which at the same time existing in another place [...] and in this consists identity. For we never finding nor conceiving it possible, that two things of the same kind should exist in the same place at the same time, we rightly conclude, that whatever exits anywhere at any time, excludes all of the same kind, and is there itself alone» (J. LOCKE, «Essay of Human Understanding», en The Works of John Locke, London, Thomas Tegg, 1823, $\mathbb{1}$ 1, p. 27, y p. 47 del vol. II).

${ }^{46}$ Kant supone una condición representativa, que sería el principio puro a priori del entendimiento (o Verstand), y una condición presentativa, que sería el fenómeno una vez que ha sido elaborado en la síntesis trascendental a través de los principios a priori del entendimiento. Un antes y un después sencillamente perfectos que separan a conciencia las condiciones de la presentación de las condiciones de la representación. Esta distinción lleva, a juicio de Saumells, a un idealismo indefendible incluso en la geometría pura. Vid. R. SAumeLLS, La ciencia y el ideal metódico, Madrid, Rialp, 1958, p. 91. 
Pronto se perdieron aquellas categorías puras del entendimiento, aunque los neokantianos del cambio de siglo (del XIX al Xx) las recordaron generosamente fuera de su contexto. Cabe que nos preguntemos si esta pérdida determinó la vuelta genuina a unos datos protocolares que debieran haber sido tratados con más respeto. No fue así, porque en el siglo Xx, Carnap, Neurath, etc., discriminaron las sensaciones humanas según esquemas previos inmanentes en la investigación. No debieran haber caído en esta trampa, porque ya Whewell, Duhem o Grassmann en el siglo XIX nos habían hecho ver que los científicos -incluso en el campo más íntimo de la geometría o de las matemáticas- seleccionan los datos relevantes para cada problema según exigencias preconcebidas que no resultan sin más desde los objetos que estudian. Además, los positivistas lógicos se empeñaron en inordinar tales datos protocolares en lenguajes lógicos o matemáticos formados al margen de tales fenómenos, y nunca ha quedado claro de dónde extraían la validez lógica, metalógica o científica de tales lenguajes.

El racionalismo imperante - aún más necesitado dentro de las teorías más empiristas- había necesitado perentoriamente dar un estatuto racional a la razón humana: ¿cómo llega la razón a ser racional? Hobbes había marcado el camino al separar incoherentemente el jus naturale existente de hecho y la lex propiamente racional. Pero entraron en un terreno peligroso, porque la experiencia demostró que no es fácil separar las condiciones materiales de la presentación de las condiciones formales de lo que es representado ${ }^{47}$. A pesar de ello consideraron que la filosofía es una ciencia racional y que, como tal, debe cobrar un estatuto autónomo frente a las representaciones de la sensibilidad. Pero la impresión que obtiene el inves-

47 Aquí se nos entrelazan temas diversos y podemos aludir a uno de ellos, a saber: cuando Hume rechaza lo que él llama la superstición de la fe en la existencia continuada de las cosas, ¿desde qué base epistemológica hace esto? Obviamente, ha de ser una base de naturaleza superior a lo que nos muestran los sentidos, pues él cuestiona precisamente la evidencia de la vista, del sentido común que nace desde la unión actual de los sentidos y la memoria, etc. En realidad, Hume se asienta en el sentido común criticista típico del iluminismo, que solía anular las evidencias sensoriales en nombre de evidencias racionales superiores. Este era un estilo que arrancaba de Descartes, que negaba las evidencias proporcionadas por los sentidos en nombre de las evidencias de la razón que partían desde las ideas innatas que habían de ser proseguidas mediante ulteriores desarrollos teoremáticos deductivos. La propuesta cartesiana tenía cierto sentido, porque negaba la objetividad de unos contenidos mentales en nombre de otros contenidos mentales que se mostraban superiores en algunas de sus aplicaciones prácticas, como vemos claramente en su teoría mecánica. Pero Hume no cree en ideas innatas; sin embargo, niega la objetividad de los contenidos mentales que nos proporcionan las impresiones sensoriales. Si le preguntamos a Hume cómo la evidencia sensorial puede volverse sobre sí misma para negar su propia realidad, su entero sistema epistemológico quedaría seriamente quebrantado. 
tigador es que fracasaron en su empeño de construir una teoría general de la sensibilidad, porque elaboraron categorías y leyes que no las proporcionaban los fenómenos suministrados por la sensibilidad. Al plantear así el tema, nos adentramos en un terreno incómodo por su simplicidad y carácter último. Es preciso traspasar los límites de la razón puramente metódica, y si planteamos el tema con tal contundencia sólo cabe intentar responder al fondo de la cuestión o rehuir plenamente el problema.

Porque la filosofía social o práctica cumple bien la primera de aquellas dos condiciones: los objetos sobre los que versa son las cosas aprehendidas por la sensibilidad (cosas tales como la pobreza, hacer celebrado un contrato, la enfermedad, trabajar por cuenta ajena o conducir un automóvil). Pero no ve cómo construir un estatuto de la racionalidad o de las conductas humanas que sea autónomo frente a los datos de la sensibilidad o frente a las acciones de los hombres, y aquí comenzaría seriamente el problema de los empiristas y positivistas cuando explican teóricamente el Derecho, ya que dejan reducidas las acciones humanas a pura facticidad que ha de ser enjuiciada por una teoría ideal o por un realidad cuasinoumenal fundamentada en alguna variante de la validez.

\section{LA DIVERSIDAD PUEDE RECLAMAR SUS DERECHOS}

Cabe preguntarse si este volver a recuperar después lo que en un inicio fue declarado falso o incapaz es una contradicción soportable que hace honor a la complejidad de la realidad. ¿Estamos ante personas de espíritu amplio y elástico capaces de dar razón de las contradicciones, o estamos ante recursos retóricos que denotan falta de creatividad e insuficiencia de los axiomas, es decir, en definitiva, del método? Parece que si se propone como sistema de ética un conjunto lógico que parte desde una base empirista, partiendo desde el dato más inicial y atómico posible, y que para autoafirmarse le es imprescindible declarar equivocadas las éticas sociales ya existentes, no es lícito volver a recuperar aquello cuya imposibilidad epistemológica y por tanto lógica componía la principal razón de ser del nuevo sistema propuesto. No parece correcto despojar a los seres humanos de su personalidad (que es quizá el único dato incomunicable que conocemos) para, en un segundo momento, negar también la individualidad en nombre de la personalidad ya desdeñada antes ${ }^{48}$.

${ }^{48}$ Los sistemas éticos pretendidamente científicos, desde sus bases conductistas o behavioristas, optan por la individualidad a costa de la personalidad. Frankl nos indica lo 
Esto lo hace Rawls cuando declara equivocadas a todas las morales comprehensivas existentes ${ }^{49}$.

Este tipo de aperturas de espíritu son posibles en un sistema ético del tipo del aristotélico, que juega en todo momento con un combinado de relatives de distinta procedencia y diferente estatuto epistemológico y ontológico, por lo que renuncia a la exactitud lógico-científica según el estilo moderno. Michel Bastit ha reeditado recientemente algunas tablas lógicas clásicas ${ }^{50}$, precisamente porque este sistema de lógica abre la posibilidad de lograr este juego en el que se combinan en cada caso una cierta cantidad heterogénea de principios normativos. Pero echar mano de los contenidos de las morales comprehensivas, cuyo rechazo inicial justificó la existencia misma de la nueva teoría de la justicia, es sólo sincretismo fácil que es resultado de una falta de teoría que trata de redimirse a sí misma contradiciéndose sin tapujos. Es el problema eterno que recae sobre quienes constituyen el objeto de su estudio por el resultado de un método impuesto antes de comenzar la investigación pero que se basan en algún dato facilitado por alguno de los métodos desechados.

El autor de estas líneas confiesa su ignorancia sobre los temas fundamentales de la ciencia: qué es el tiempo, qué es el espacio. Además, está convencido de que el hombre nunca llegará a dar una explicación satisfac-

siguiente: «¿Cuáles son las razones que llevan al psicólogo con ceguera para la autotrascendencia y, consecuentemente, para la captación de sentidos y razones? Si es un psicoanalista, querrá sustituir los motivos por ciertas tendencias e instintos como causas de la conducta humana. Si es un behaviorista, querrá ver en la conducta humana el mero efecto de los procesos de condicionamiento y aprendizaje. Si no existen sentidos, ni razones, ni elecciones, deben suponerse otros determinantes, de una manera u otra, para reemplazarlos. En tales circunstancias, la condición misma de humanidad se deja de lado en la observación de la conducta humana. Si la psicología o, en este caso, la psicoterapia, ha de ser rehumanizada, debe hacerse siendo conscientes de la autotrascendencia más bien que ignorándola» (V. E. FrankL, La idea psicológica del hombre, trad. de F. Fernandez Turienzo y Omar Lasarte, . $^{\text {a }}$ ed., Madrid, Rialp, 1986, p. 29).

49 Rawls indica: «El hecho de este razonable pluralismo debe distinguirse del pluralismo como tal». Le mueve a pensar así su comprobación del hecho de que «se afirman o profesan muchas doctrinas comprensivas razonables, y no todas pueden ser verdaderas (en realidad, ninguna de ellas puede ser vera)» (J. Rawls, Liberalismo político, Conferencia I, «Ideas Fundamentales», trad. de S. R. Madero, México, FCE, 1996, p. 76). A veces se vuelve agresivo en su rechazo de los que no piensan como él, y escribe: «Por supuesto, quienes insisten en sus creencias también insisten en que sólo sus creencias son las verdaderas: imponen sus creencias porque - al menos así lo dicen - sus creencias son veras, no porque sean sus creencias» (ibid., p. 77). Ahora no queda nada del «razonable pluralismo» del que hablaba páginas antes.

${ }_{50}$ M. Bastit (ed.), Tables de logique. Sur l'Introduction de Porphyre, les Catégories, le l'Interprétation et les Premiers Analytiques d'Aristote, Paris-Budapest-Torino, L'Harmattan, 2003. Reproduce la teoría lógica del cardenal Zarabella. 
toria de estos temas. En planos más concretos, ¿cómo conciliar a Newton con Planck? Pero asoma un atisbo: gracias a la tecnología que producimos de acuerdo con la mecánica de Newton, fabricamos aparatos que comunican eficaz y realmente a muchas personas. De un modo igualmente real, sabemos que el deber de pagar impuestos es un deber jurídico completamente distinto de los deberes de un usufructuario: ¿existe algún problema para reconocer que el usufructo es una realidad distinta de los impuestos? Ante este problema, Hobbes, Locke o Hume se remontan a fenómenos o percepciones que no pueden dar cuenta de las estructuras más complejas de la realidad humana que los hacen posibles.

Si nos olvidamos de hacer una teoría, es decir, un conjunto más o menos axiomático que componga un sistema sin contradicciones, quizá podamos estar en condiciones de proponer una doctrina. Kant se ocupó de distinguir ambas nociones, pero resulta obvio que no me remito a las intuiciones kantianas. Parece, más bien, que siempre tendremos presente la posibilidad de recurrir a fuentes de distinto status para estar en condiciones de dar cuenta de la complejidad de lo real. Pues los seres humanos somos libres de algunos modos y a veces, y podemos conocer de maneras distintas y también ocasionalmente. Los modernos sólo tienen en cuenta la causalidad eficiente —una secuela de su imagen mecanicista del mundo-, unas causas que siempre operan desplazando «lógicamente», esto es, de atrás a adelante, o desde el antes al después, por impulsiones guiadas por el principio de la ubicuidad o no-contradicción. Les es ajena la causalidad final, y si establecen teleologías (más que de teleologías hay que hablar de simples estrategias teleológicas) se trata de constructos sintéticos a priori, cuyo núcleo más interno está constituido por la simple causalidad mecánica de acuerdo con reglas de traducción —esto es, elementos functores y algoritmos- predeterminados. Desde luego, mientras alguien se empeñe, a pesar de todo, en seguir en el interior de los moldes veteromecánicos, tendrá que limitarse a lo que puede explicar de acuerdo con tal tipo de causalidad eficiente. En tales casos, la visión materialista propia de la máquina es anticipada, como esquema necesario a priori, para discernir las conductas adecuadas.

Esto es irracional. Sucede, en última instancia, que el término «realidad» aplicado a las ciencias naturales es distinto de lo que podemos llamar la «realidad humana», ya que este término, usado en ambos casos, es excesivamente equívoco. Aquellos viejos moldes mecánicos tanto valen como engañan porque, incluso en el plano de la física, la mecánica cuántica nos muestra que los movimientos más íntimos de nuestra realidad no 
son mecánicos, sino tendenciales o teleológicos, y no es cuestión que el estudioso de las ciencias humanas se desanime porque haya de proceder de forma similar a la de los físicos. El siglo XVII condenó a las causas finales y el siglo xx las ha recuperado, de modo que la res extensa cartesiana ha resultado ser mucho más res cogitans de lo que pensaban los pioneros de la mecánica moderna ${ }^{51}$. Esta comprobación no nos puede llevar sin más hacia una entelequia inocente que mantenga alguna especie de teleología universal. Pero sí desmonta la universalidad epistemológica del paradigma mecánico-eficiente.

\section{PARA TERMINAR}

Hemos asistido a una pequeña locura de ideas entretejidas sin mucho orden. El problema aludido se ha nos planteado ante todo por la función omniabarcante de la conciencia objetiva que es propia de la geometría. Descartes se representó un espacio plano (parece ser el mismo de Einstein cuando propone el ejemplo de la cama elástica) y cabe acusarlo ante el tribunal de la razón de haber polarizado gratuitamente este espacio así concebido. Era un espacio sin relieves, que no conocía más que las ubicaciones de arriba/abajo, izquierda/derecha y adelante/detrás; ubicaciones en rigor irrelevantes para ellos porque la formación de la realidad habría sido fortuita, violenta y amoral. De acuerdo con la visión mecánica subyacente, todos los problemas - también los del hombre- se resolverían en una cadena prácticamente infinita de causas y efectos en el sentido indicado, según las reglas del mos geometricus. Frege y Peano se esforzaron por mostrar los fundamentos lógicos de las matemáticas y Gödel demostró de forma matemáticamente impecable que todo conjunto axiomático suficientemente completo supone necesariamente factores que no se pueden demostrar desde tal conjunto axiomatizado y que no se contienen en él.

Pero el espacio único y plano cartesiano hace irrelevantes estas dificultades ante el gran público; en él, todos los gatos son pardos, y tanto podemos ir de atrás a adelante como de adelante a atrás, como si la degeneración necesaria que llamamos entropía y como si las cualidades emergentes (o Gestalten) no existieran. Esta representación del espacio conlleva una

51 Tirso de Andrés explica que si el cogito, si pensar, consiste en una pura capacidad racional o formal, pertenece también a la máquina extensa material. En la res extensa hay más logos y capacidad de logos de lo que nunca pensó el racionalismo. Vid. T. DE ANDRÉs, Homo «cybersapiens»..., op. cit., p. 79. 
imagen geométrica universal — que es el fundamento de las teorías modernas sobre el Derecho- en la que no existen relieves distintos o puntos, porque, como explicó Hegel, el punto es la negación del espacio ${ }^{52}$, y la conciencia necesita (afectiva o psicológicamente) anteponer una idea de la totalidad que sea necesariamente anterior a las realidades concretas, a las que homogeneiza, en definitiva, desde las propiedades del espacio humano que impone este mos geometricus. Así, las especies son explicadas por los géneros, y éstos desde el todo universal. Aunque más bien parece que el sentimiento o la vivencia de este único espacio de discusión (llamado espacio humano y que por eso tiene un toque especialmente humanista) constituye una gran capa que encubre una multitud de miserias. Temo que algunos incurren en lo que denuncia Tirso de Andrés: «La pregunta absoluta, madre de todas las preguntas, que se intenta hacer desde el vacío a otro vacío mayor, no deja de ser una pretenciosa necedad muy del gusto decimonónico» ${ }^{53}$.

52 Hegel expuso la dificultad más grave de estos métodos fenomenistas en su Enzyklopädie der philosophischen Wissenschaften, $\mathbb{\$} 254$, Zweiter Teil, en donde explica que: «Der Punkt, das Fürsichsein, ist deswegen vielmehr die und zwar in ibm gesetzte Negation des Raums» (cito por la edición de Frankfurt am Main, Suhrkamp, 1970).

53 T. DE ANDRÉs, Homo «cybersapiens»..., op. cit., p. 129. 